\title{
Geometria para as crianças em tempos de Matemática Moderna em Minas Gerais: analisando novas fontes
}

\section{Resumo}

O presente artigo propõe discutir as marcas do Movimento da Matemática Moderna (MMM) presentes em novas fontes analisadas nos materiais utilizados e/ou confeccionados pela professora Myriam Boardman de Oliveira, que atuou no ensino primário em Minas Gerais entre as décadas de 1960 e de 1980. Fundamentam esta investigação: Prost (1996), Bloch (2002), Choppin (2002), Chervel (1990), Chartier (1990). Na perspectiva de uma pesquisa em história da educação matemática (HEM), optou-se por um aprofundamento em Valente (2007; 2013), Leme da Silva e Valente (2014), Oliveira (2011; 2015). O confronto dos resultados de Mendonça (2016) com os nossos evidenciam o estudo das figuras geométricas com a utilização da teoria de conjuntos, principalmente pela linguagem; precisão da linguagem utilizada e com a utilização, mesmo que de forma introdutória, de conceitos topológicos. A geometria euclidiana é evidenciada com atividades tanto de construção (utilizando compasso, régua, transferidor) e de observação com instrumentos diversos (palitos, barbantes, entre outros). Alguns pontos defendidos pelo ideário do MMM estavam presentes no material da professora, mesmo não sendo tão evidentes.

Palavras-Chave: História da Educação Matemática; Geometria, Movimento da Matemática Moderna 


\section{Geometry for children in Modern Mathematics times in Minas Gerais: analyzing new sources}

Thiago Neves Mendonça

Abstract

The present article proposes to discuss the marks of the Movement of Modern Mathematics (MMM) present in new sources analyzed in the materials used and / or made by Professor Myriam Boardman de Oliveira, who worked in primary education in Minas Gerais between the decade of 1960 and 1980. Grounds this research: Prost (1996), Bloch (2002), Choppin (2002), Chervel (1990), and Chartier (1990). In the perspective of a research in the history of mathematical education (HEM), we opted for a deepening in Valente (2007; 2013), Leme da Silva and Valente (2014), Oliveira (2011; 2015). The comparison of the results of Mendonça (2016) with ours show the study of geometric figures with the use of set theory, mainly by language; accuracy of the language used and the use, even introductory, topological concepts. Euclidean geometry is evidenced with activities of both construction (using compass, ruler, protractor) and observation with various instruments (sticks, string, among others). Some points defended by the MMM's ideas were present in the teacher's material, even though they were not so obvious.

Keywords: History of Mathematics Education; Geometry, Modern Mathematics Movement 


\section{Introdução: um viés para a pesquisa em história da educação matemática}

Para uma pesquisa em uma perspectiva histórica, as questões postas pelo pesquisador são, de fato, importantes, tal como salienta Valente (2007).

O ofício do historiador não parte dos fatos como um dado a priori. Assim, cabe perguntar o que precede o estabelecimento dos fatos? Como resposta, na sua quarta aula, Antoine Prost responde que são as questões do historiador, suas hipóteses iniciais. Assim, não haverá fatos sem questões prévias para o seu estabelecimento. Em síntese, não existem fatos históricos sem questões postas pelo historiador (VALENTE, 2007, p. 31).

Há uma ruptura no modo de se fazer história, fundamentada, principalmente, no trabalho do historiador francês Marc Bloch (2002). O autor redefine o ofício do historiador, ao trazer uma metodologia por ele denominada método regressivo, que seria o reconhecer o passado pelo presente, e vice-e-versa.

A história compreende-se em dois tempos: conhecer os fatos históricos e explicá-los de forma coerente (PROST, 1996). Há, então, uma regra: não há história sem fatos, ou seja, não se pode fazer afirmações sem as devidas provas documentais para isso. Fatos esses que se constroem através de traços, rastros do passo deixados no presente. Não haverá, ainda, fatos sem as questões prévias do historiador, postas de modo a buscarem preencher as lacunas do conhecimento histórico, porém “[...] a verdadeira lacuna não é um objeto suplementar, onde a história não foi feita. Trata-se de questões para as quais os historiadores não têm respostas [...]” (PROST, 1996, p. 85).

A trajetória de uma pesquisa histórica pode ser sintetizada por alguns passos, a saber: o interesse de pesquisa, a formulação de questões históricas legítimas, o trabalho com documentos e a construção de um discurso que seja aceito pela comunidade (cf. VALENTE, 2007). Prost (1996) aponta que, para trabalhar com as fontes históricas, deve-se fazer críticas, confrontando a fonte com tudo o que é conhecido pelo assunto, sobre o lugar e sobre o momento a que pertence essa fonte. A saber, praticar a história da educação matemática (HEM) implica, de forma geral, buscar respostas para questões como "por que pensamos em reformas sobre o ensino de matemática?” ou ainda "por que ensinamos o que ensinamos em Matemática?”, entre outras. O ofício do historiador inicia-se no processo de interrogação feito aos traços deixados pelo passado, o que conduz a fontes de pesquisas por essas questões; finalizando na construção desses fatos históricos, representados pelas respostas dadas às questões propostas.

Para essa pesquisa, a análise dá-se em livros didáticos, em programas de ensino e em cadernos de professores. Choppin (2002) considera os livros didáticos como fontes privilegiadas que se articulam às prescrições indicadas em programas oficiais, e que, na 
maioria das vezes, estão de acordo com regulamentos escolares. Para que uma análise de um manual didático tenha qualidade, o pesquisador faz algumas observações.

Inicialmente, um trabalho de coleta e de tratamento sistemático das fontes: é preciso empreender ou proceder a constituição e ao desenvolvimento de grandes instrumentos de pesquisa, monografias de editoras, repertórios de textos oficiais ou bancos de dados bibliográficos, e colocá-las, tanto quanto possível, à disposição da comunidade científica através da internet. Em segundo lugar, um trabalho de reflexão metodológica: uma das características essenciais da pesquisa sobre o livro e edição escolares é sua interdisciplinaridade, no sentido amplo, e um dos principais perigos aos quais se expõe qualquer pesquisador, trabalhando só, isolado é de dar a uma realidade complexa uma análise reducionista, até mesmo errônea. Então, se o manual é o produto de competências diversas, por que não seria o mesmo para a pesquisa que o toma como objeto? (CHOPPIN, 2002, p. 23).

Sobre a análise dos livros didáticos, Choppin (2002) destaca alguns pontos, tais como: a amostragem; as condições regulamentares técnicas e econômicas; a defasagem temporal; o manual como imagem e espelho e como instrumento. Percebe-se, assim, que analisar um livro didático requer observar algumas etapas e alguns elementos importantes, como o tempo, as edições, as atualizações, os destinatários, a linguagem, as figuras, entre outros.

Uma disciplina escolar, no caso a Matemática, não pode ser estudada, historicamente, somente pela apresentação dos conteúdos a serem ensinados. O estudo da forma de como são ensinados esses conteúdos é tarefa indispensável do historiador, que irão

[...] detalhar suas etapas, descrever a evolução da didática, pesquisar as razões da mudança, revelar a coerência interna dos diferentes procedimentos aos quais se apela, e estabelecer a ligação entre o ensino dispensado e as finalidades que presidem a seu exercício (CHERVEL, 1990, p. 26).

Em cada disciplina escolar há uma variável histórica,

[...] cujo estudo deve ter um papel privilegiado na história das disciplinas escolares. É uma variável que, em geral, põe em evidência algumas grandes tendências: evolução que vai do curso ditado para a lição aprendida no livro, da formulação estrita, até mesmo lapidar, para as exposições mais flexíveis, da recitação para a impregnação, da exaustividade para a seleção das linhas principais (CHERVEL, 1990, p. 45).

Sobre cultura escolar, recorre-se a Julia (2001), que considera três elementos essenciais: espaço escolar, cursos graduados em níveis e corpo profissional. São esses elementos que justificam a restrição cronológica de uma pesquisa histórica que será realizada pelo pesquisador.

Os livros didáticos e os documentos históricos possuem diversas funções, além das imediatas, e que uma ideia de apropriação seria observar a diversidade de usos desses textos. ISSN 2526-2882 
Assumimos o conceito de apropriação, a partir de Chartier (1990) que coloca em evidência a pluralidade dos seus empregos.

A apropriação, tal como entendemos, tem por objetivo uma história social das interpretações, remetidas para as suas determinações fundamentais (que são sociais, institucionais, culturais) e inscritas nas práticas específicas que as produzem. Conceder deste modo atenção às condições e aos processos que, muito concretamente, determinam as operações de construção do sentido (na relação de leitura, mas em muitas outras também) é reconhecer, contra a antiga história intelectual, que as inteligências não são desencarnadas, e, contra as correntes de pensamento mais invariáveis devem ser construídas na descontinuidade das trajectórias históricas (CHARTIER, 1990, p. 26-27).

\section{Um pouco de história: o Movimento da Matemática Moderna (MMM) e o ensino de Geometria para as crianças, no Brasil}

Com a tradução das Memórias de Condorcet, nas primeiras décadas do século XIX, desenvolveu uma ideia central de como a Geometria deveria ser pensada e ensinada para o curso primário: uma geometria prática, útil às especificidades da agrimensura, da medida de terras. Nota-se esse caráter prático nas construções de linhas, ângulos, figuras e nos desenhos em perspectivas dos sólidos geométricos (LEME DA SILVA; VALENTE, 2014).

Segundo Valente (2013), a geometria euclidiana figurou, no ensino primário, caracterizada de acordo com o nível de conceituação, como definido por Klein (1849-1925), ao estudar figuras congruentes entre si, que permanecem invariantes quando seus elementos são submetidos à transformações isométricas (rotações, translações, reflexões em retas e suas composições). Além disso, a geometria de Euclides aborda o estudo de figuras semelhantes e o sistema de axiomas de Hilbert, de Brirkhoff, de Pogorelov, entre outros.

Antes do MMM, os objetos de ensino para as crianças tomavam como referência os Elementos de Euclides, as figuras geométricas mais simples e suas propriedades. A estabilidade para ensinar esses conteúdos é rompida com a divulgação dos estudos de Jean Piaget, cuja ideia de um novo elementar dará, à geometria euclidiana, uma nova acepção: não será mais considerada como conteúdo matemático do ensino primário. Defendendo a ideia do estágio topológico da criança, Jean Piaget, em parceria com Bärbel Inhelder, publica $L a$ Represéntation de l'Espce chez l'Enfant, em 1947, cuja tradução para o português se deu em 1993 com o título A representação do espaço na criança, e explica que a criança passa pelo estágio topológico antes do euclidiano.

O ensino de Geometria poderia ganhar muito ao adaptar-se à evolução espontânea das noções, ainda que - acabamos de pressenti-lo - tal evolução seja muito mais próxima da construção matemática do que o são a maioria dos manuais ditos "elementares". Tem sido dito que a "teoria dos conjuntos" de Cantor deveria ser ensinada na escola primária. Nós não estaríamos longe de 
pensar o mesmo no que se refere aos elementos da topologia... (PIAGET; INHELDER, 1993, p. 12 apud LEME DA SILVA; VALENTE, 2014, p. 71).

Uma outra proposta para o ensino de Geometria para as crianças é defendida por Dienes, em 1960, através do Office Central de Libraire (OCDL), em sua coleção First years in Mathematics / Les premiers pas em mathématiques, editados no Brasil no final da década de 1960. Um dos volumes dessa coleção, intitulado Exploration of space and pratical measurement / Exploration de l'espace et pratique de la mesure, editado no Brasil em 1977, destacam-se algumas ideias fundamentais do autor.

A geometria é a exploração do espaço. Uma criança, desde seu nascimento, explora o espaço. Primeiramente o olha, depois sonda com seus braços e pernas visando a descoberta, e enfim se descola nele. É preciso um tempo bastante longo para desenvolver as ideias de perspectiva, de distância, de profundidade; noções como as de dentro e fora, diante e atrás, antes e depois, e assim por diante [...] As primeiras noções de geometria não têm nada a ver com medida. Uma criança preocupa-se muito pouco com a distância exata dos objetos, de seus movimentos ou do ângulo sob o qual as coisas são vistas (DIENES, GOLDING, 1977, p.1 apud VALENTE, 2013, p. 170-171).

No Brasil, a coleção Curso Moderno de Matemática para a escola elementar, escrita por Manhúcia Perelberg Liberman, Anna Franchi e Lucília Bechara, foi um dos primeiros livros publicados para as séries iniciais. Medina (2007) aponta algumas possíveis apropriações das ideias de Dienes no primeiro volume da coleção, a saber: (i) a utilização de fichas de trabalho com folhas soltas; (ii) a incorporação de ilustrações de objetos próximos à realidade infantil; (iii) a utilização de materiais concretos e, por fim, (iv) a manipuláveis como recursos didáticos.

Leme da Silva e Valente (2014) constatam pontos relevantes sobre a geometria para o ensino primário presentes nessa coleção, isto é, atividades que levam as crianças a traçarem caminhos partindo de um ponto e chegando a um outro ponto, as ideias de curvas (abertas e fechadas, simples e não simples), interior de curvas fechadas, entre outros tópicos que não estavam presentes em outras coleções anteriores. Na coleção, há, também, a linguagem de conjuntos, trazendo de forma diferenciada a abordagem das relações geométricas. A ideia de que os segmentos de retas, por exemplo, eram considerados iguais; com a nova linguagem tornam-se congruentes, por não serem constituídos pelo mesmo conjunto de pontos e sim por terem a mesma medida. Percebe-se uma articulação entre os conceitos topológicos e a geometria euclidiana, utilizando a linguagem de conjuntos. Na época da edição dessa coleção, alguns livros didáticos passaram a conter temas da topologia.

No estado de Minas Gerais, o Programa do Ensino Primário de Minas Gerais (PEP$M G$ ), publicado em 1965, foi dividido em quatro volumes, um para cada série, e contém, de acordo com Mendonça (2016), de forma incipiente, marcas do MMM. A começar pelos termos

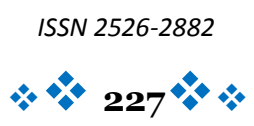


utilizados em textos, tais como na introdução, "exigências do mundo moderno" (MINAS GERAIS, 1965, p. 7). Além disso, há menção à Matemática Moderna na apresentação do PEPMG, no volume 1, conforme destaca o trecho a seguir.

Com referência ao conteúdo damos maior importância a três aspectos que caracterizam o ensino da matemática moderna: - o sistema de numeração, básico para compreensão dos processos quantitativos; - a geometria que merece um estudo mais sistematizado na escola elementar; - a introdução de rudimentos de álgebra, para familiarizar os alunos com as sentenças matemáticas [...] (MINAS GERAIS, 1965, p. 301)

Na bibliografia do PEP-MG, no volume 4, são encontradas três obras de Piaget, a saber: La formación del símbolos em el niño, L'enseignement des Mathématiques e $A$ linguagem e o pensamento da criança. Sobre as atividades de geometria, presentes no PEPMG, Oliveira (2015) destaca que estavam alinhadas com o ideário do MMM, por preocuparemse com o raciocínio em substituição à memorização, com a valorização da descoberta no processo de aprendizagem e com o percurso de ensino por meio de etapas específicas (intuição, experimentação e generalização). Não se encontram ideias de topologia, segundo a autora.

À guisa de conclusão, o MMM, no ensino primário brasileiro, esteve mais relacionado a uma proposta experimentalista, ou seja, o aluno deveria estar em atividade constante durante a construção do conhecimento com a utilização de materiais concretos e o professor seria o orientador das descobertas que seriam intuitivas, num primeiro momento, e posteriormente sistematizadas e formalizadas. Além disso, houve uma grande quantidade de publicações para auxiliar os professores e o papel da imprensa pedagógica foi produzir o de “[...] consenso e de legitimar ações e discursos sobre a Matemática Moderna, tentando modelar as práticas, em nome de um saber, que estava para ser ensinado nas escolas [...]” (OLIVEIRA, 2011, p. 135).

No cenário da MMM, o ensino de Geometria tomava uma ordem inversa de aprendizagem, passava inicialmente pelas noções topológicas e retornando à geometria euclidiana de sempre. Os diferenciais do MMM no ensino primário estão na metodologia com apropriações de Piaget e de Dienes. Em particular, no estado de Minas Gerais, já se observam traços do MMM no Programa do Ensino Primário de Minas Gerais. Mendonça (2016) atestou que, na bibliografia, havia uma série de obras de Piaget, além do uso do termo "matemática moderna” que é observado na apresentação do volume destinado à primeira série.

Com referência ao conteúdo damos maior importância a três aspectos que caracterizam o ensino da matemática moderna: - o sistema de numeração, básico para compreensão dos processos quantitativos; - a geometria que merece um estudo mais sistematizado na escola elementar; - a introdução de rudimentos de álgebra, para familiarizar os alunos com as sentenças matemáticas [...] (MINAS GERAIS, 1965, p. 301, grifos nossos). 
Para Oliveira (2015), as atividades de Geometria propostas nesse programa já estavam alinhadas ao ideário do MMM no Brasil, pois, segundo ela, essas atividades tinham a preocupação com o raciocínio em substituição à memorização, a valorização da descoberta no processo de aprendizagem e o percurso de ensino por etapas: intuição, experimentação e generalização. Há de ressaltar-se que, mesmo de forma incipiente, o PEP/MG traz algumas ideias do MMM, antecedendo à publicação do Programa da Escola Primária do Estado de São Paulo (PEP/SP), publicado em 1969. Esse contou com a colaboração majoritária de professores e de integrantes do Grupo de Estudos do Ensino de Matemática (GEEM), como verificou Medina (2007). Esse programa apresentava fortes traços do MMM, como por exemplo, as noções topológicas baseadas na ideia estrutural, e retomando a teoria dos conjuntos.

\section{O caminho até aqui: análises de algumas fontes do acervo da professora Myriam}

A professora Myriam Boardman de Oliveira formou-se em 1956 pela Escola Normal Oficial de Juiz de Fora. Foi aprovada em um concurso para bolsista do estado de Minas Gerais, entre 1966 e 1968, para estudar e para receber o diploma de orientadora e de diretora de escola. Trabalhou no Grupo Escolar José Eutrópio de 1962 a 1970. Foi supervisora escolar no Grupo Escolar Maria de Magalhães Freitas entre 1970 a 1972. De 1973 a 1977, trabalhou no Jardim da Infância Mariano Procópio como supervisora e diretora. Ocupou o cargo de supervisora do Grupo Duque de Caxias. Além disso, ela prestou concurso para a prefeitura de Juiz de Fora, onde foi nomeada e trabalhou por sete anos como professora de alunos com 4 e 5 anos. Aposentou-se em 1986.

Do acervo da professora Myriam, Mendonça (2016) analisou as seguintes fontes: a coleção Curso Completo de Matemática Moderna para o Ensino Primário (CCMMEP); o Caderno de Exercícios (CdeE) e o Caderno de Geometria (CdeG). Para realizar a análise desse acervo, foram elencadas algumas categorias para a exploração desses materiais, a saber: (i) presença da topologia; (ii) construções geométricas; (iii) linguagem de conjuntos; (iv) referência a Dienes e a Piaget; (v) uso de imagens e diagramas; (vi) uso de materiais didáticos; e, por fim (vii) justificativa de propriedades.

A CCMMEP foi escrita pelas professoras Tosca Ferreira e Henriqueta de Carvalho. Ambas foram professores de Grupos Escolares em São Paulo, supervisoras do Ensino de Matemática, professores de cursos de admissão e conferencistas de cursos intensivos de Matemática Moderna em alguns estados, tais como Paraná, Minas Gerais e Santa Catarina. Essa coleção destinava-se aos professores, por se observar: o decálogo (dez sugestões para os professores); sugestões de atividades para serem realizadas com as crianças e como executá- 
las; divisão do conteúdo para o ano, separando os tópicos por meses, como uma espécie de cronograma anual.

Arruda (2011) identifica que o nome de Henriqueta aparece juntamente com o de Manhúcia Liberman, por serem professoras brasileiras ligadas ao MMM no primário. Na coleção encontra-se uma nota, escrita pelas autoras e destinada aos professores, que as noções introduzidas na obra devem ser ordenadas dentro de uma graduação, e que o grau de dificuldade requer uma certa dosagem pedagógica. Percebe-se, dessa forma, uma possível apropriação dos estudos piagetianos.

Figura 1: Correspondência biunívoca.

Exemplos:

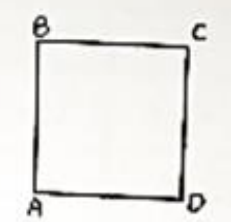

conjunto de lados quadrado

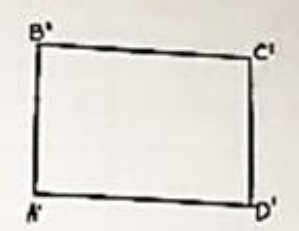

conjunto de lados do retangulo

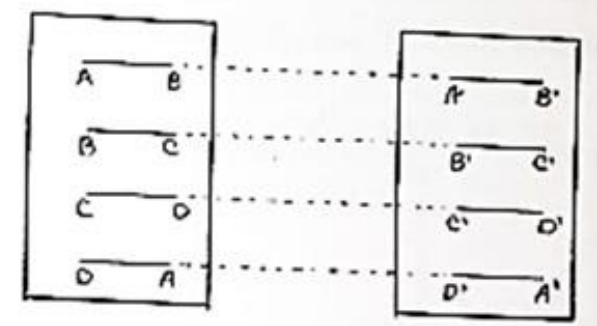

Os conjuntos de lados do quadrado estão com correspon. déncia biunivoca. Analisar os lados - lados perpendiculares
entre si e paralelos dols a dois.

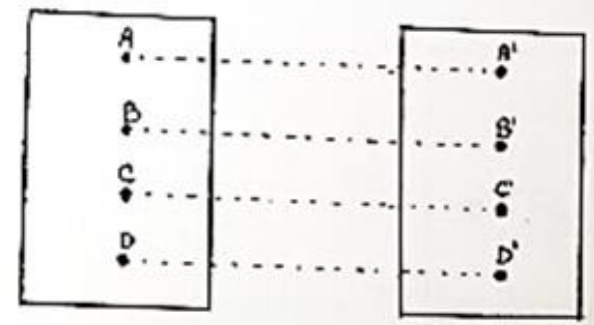

Os conjuntos de vértices do quadrado e do retângulo estāo em correspondência biunivoca.

$$
-163-
$$

Fonte: CCMMEP. $3^{\circ}$ volume. 
Sobre a geometria presente na CCMMEP, Mendonça (2016) verifica haver a presença da geometria plana e espacial, com exercícios que envolvem as linhas, preocupando-se com a linguagem matemática adequada. Além disso, observa que, ao tratarem sobre área do quadrado, as autoras definem que "[...] a parte interna, isto é, o conjunto de todos os pontos internos desse contorno é que forma o quadrado [...]” (CARVALHO, FERREIRA, s/d). Além disso, há figuras que indicam divisão de conjuntos, tais como: conjuntos de lados e de vértices de um quadrado. As autoras usam também o termo correspondência biunívoca para tratarem da correspondência dos lados do quadrado e a correspondência entre os vértices do quadrado e do retângulo.

A indicação de utilização de materiais, como o compasso e a régua, para traçar a circunferência, também está presente na CCMMEP. Para as autoras, os alunos devem saber trabalhar com esses instrumentos e ainda orientam em como utilizar tais materiais, conforme a Figura 2, a seguir.

Figura 2: Orientação de utilização do compasso e régua.

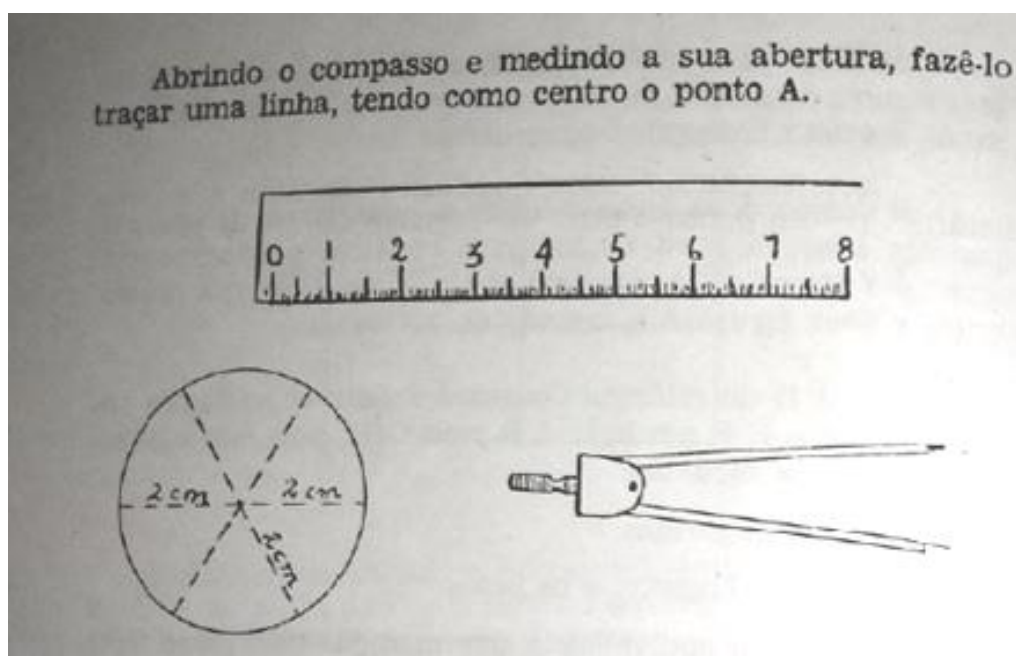

Fonte: CCMMEP. $3^{\mathrm{o}}$ volume.

Outra observação apontada por Mendonça (2016) está no fato da utilização da teoria de conjuntos para se tratar de área de figuras planas. As autoras escrevem sobre a área do quadrado dividindo a figura em nove quadrados menores, três em cada linha e essas linhas são denominadas subconjuntos. As anotações indicam o cálculo da área como sendo a união da quantidade de elementos que cada um desses subconjuntos possui, com a utilização do símbolo de união (U). As áreas das demais figuras planas são justificadas com a utilização de imagens. 
Figura 3: Linguagem de conjuntos para explicar área do quadrado

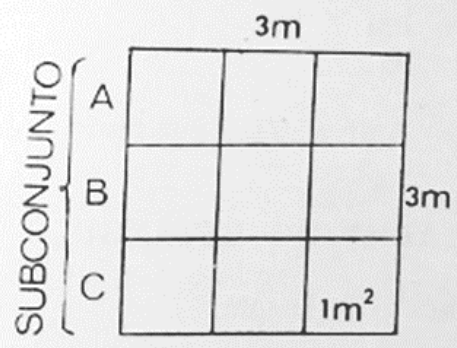

Fàcilmente calculará:

$$
\begin{gathered}
\text { A U B U C }=\text { D } \\
3 m^{2}+3 m^{2}+3 m^{2}=9 m^{2} \\
\text { ou } \\
3 m \times 3 m=9 m^{2}
\end{gathered}
$$

o que equivale a dizer que a área de um quadrado é igual ao produto de seus lados.

$$
\begin{aligned}
& A=1 \times 1 \\
& A=1^{2}
\end{aligned}
$$$$
-273-
$$

Fonte: CCMMEP. $4^{\circ}$ volume.

Novamente, atesta-se a presença da linguagem de conjuntos quando as autoras explicam o que são figuras geométricas iguais e congruentes, destacando uma sutil diferença com uma certa precisão de linguagem.

O conceito de igualdade é o ponto essencial, e deve ficar bem ensinado. Em igualdade de conjunto o aluno estudou que, a igualdade de conjunto só é real, quando os elementos de um conjunto também são os elementos do outro [...] Na igualdade das figuras geométricas, o mesmo princípio é aplicado: portanto, ao se dividir um quadrado ou um retângulo em dois triângulos, os triângulos resultantes não são iguais. (CARVALHO; FERREIRA, s/d, p. 303).

A CCMMEP possui, portanto, algumas apropriações do ideário do MMM e, quando se analisa todos os seus 5 volumes, observa-se a presença de todas as categorias para análise, anteriormente elencadas.

O CdeE da professora Myriam foi confeccionado entre 1966 e 1968 (não datado), durante o período em que a professora era bolsista no curso de Administração Escolar no estado de Minas Gerais. No caderno, observam-se exercícios de Matemática, de Português e de Metodologia. Há, apenas, dois exercícios sobre a geometria: em um deles, é nítida a preocupação com a aritmética (efetuar contas); no outro, também, há essa preocupação, mas se tem uma maior importância para a geometria por se tratar de um exercício que necessita de conceitos como ângulos, observação de figuras planas e espaciais. Observe a figura 4. 
Figura 4: Recorte do exercício sobre a horta e o exercício sobre figuras geométricas.
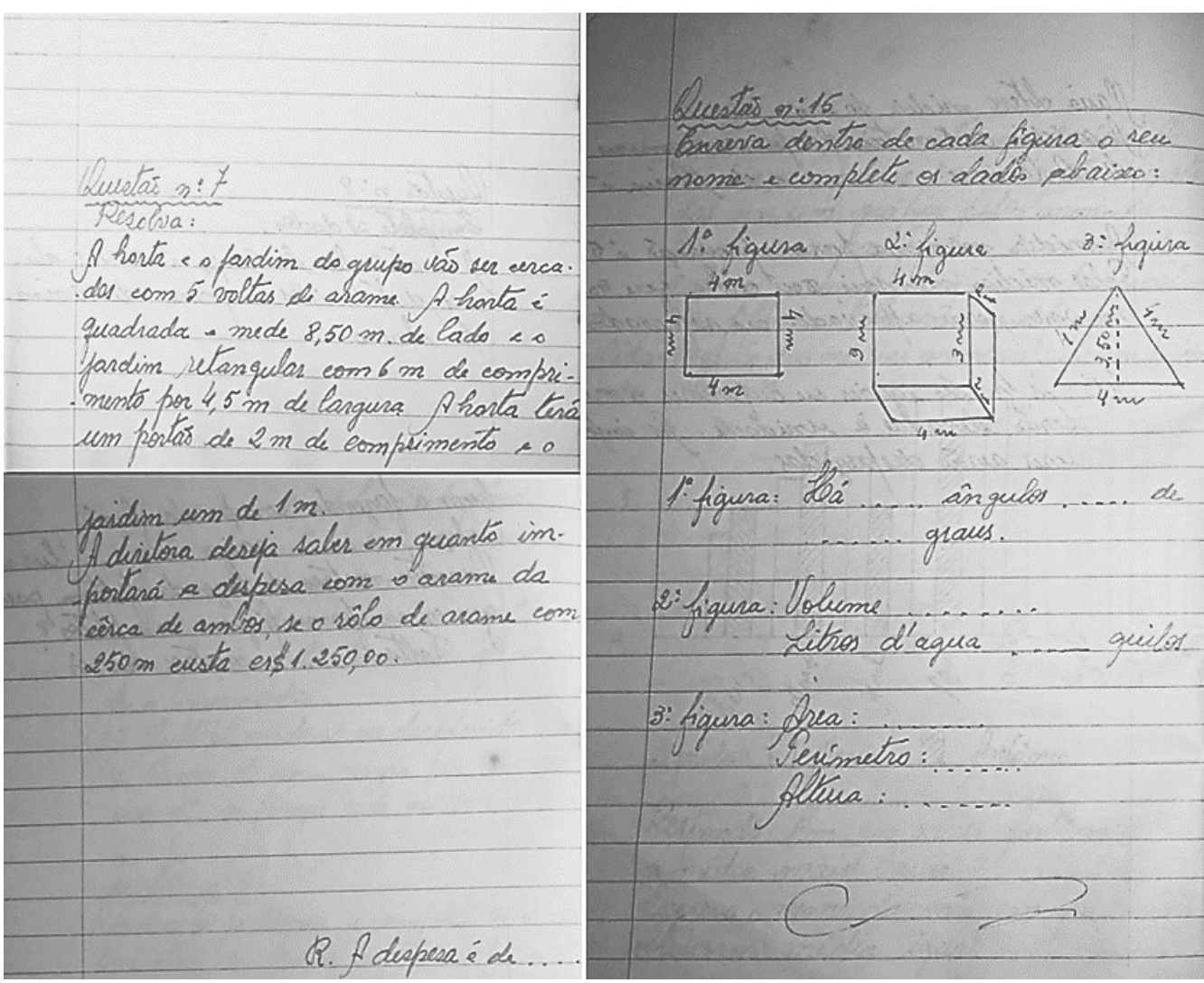

Fonte: Recorte do Caderno de Geometria da professora Myriam.

Transcrição: “Questão ${ }^{\circ} 7$ - A horta e o jardim do grupo vão ser cercados com 5 voltas de arame. A horta é quadrada e mede $8,5 \mathrm{~m}$ de lado e o jardim retangular com $6 \mathrm{~m}$ de comprimento por 4,5 $\mathrm{m}$ de largura. A horta terá um portão de $2 \mathrm{~m}$ de comprimento e o jardim um de $1 \mathrm{~m}$. A diretora deseja saber em quanto importará a despesa com o arame da cerca de ambos se o solo de arame com $250 \mathrm{~m}$ custa $\mathrm{Cr} \$ 1.250,00$.

Transcrição: Questão $\mathrm{n}^{0} 15$ - Escreva dentro de cada figura o seu nome e complete os dados abaixo: $1^{\mathrm{a}}$ figura: Há ... ângulos ... de ... graus; $2^{\mathrm{a}}$ figura: Volume ... Litros d'água .... quilos;

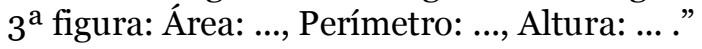

No CdeG, escrito em 1971, é possível identificar algumas definições de elementos introdutórios à geometria, tais como ângulos e suas classificações. Em relatos da professora Myriam (cf. MENDONÇA, 2016), obtém-se a informação de que ele foi confeccionado com conteúdo e com exercícios de preparação para o vestibular do curso de Pedagogia, do Centro de Ensino Superior de Juiz de Fora, mas não foi finalizado. Na parte teórica do caderno observam-se retas e suas classificações, distâncias entre pontos e retas, lugar geométrico, triângulos e suas classificações, semelhança. Em alguns exercícios pode-se observar a necessidade de conhecimentos geométricos, conforme figura 5 a seguir. 
Figura 5: Exercício no Caderno de Geometria.

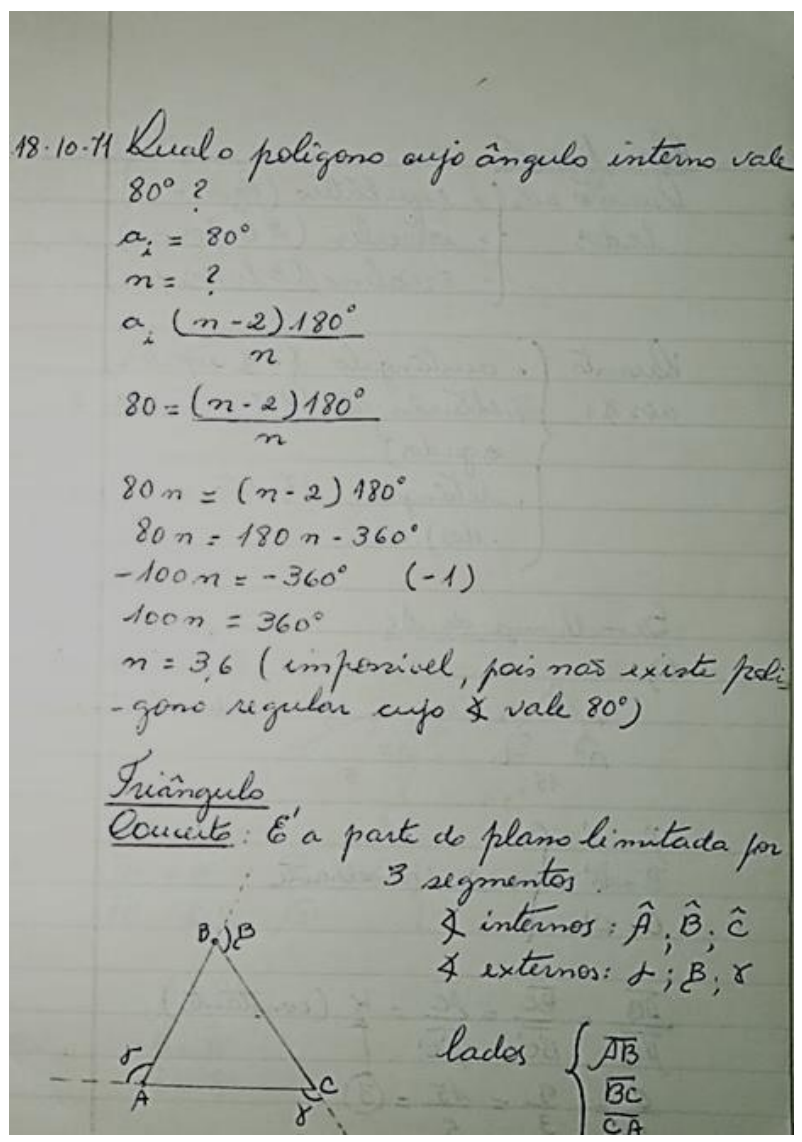

Fonte: Recorte do Caderno de Geometria da professora Myriam.

Nos cadernos, não são observados traços do MMM; tampouco alguma das categorias elencadas. A geometria proposta, nessas fontes, é a plana e a espacial, com poucos exercícios que envolvem, de fato, conceitos geométricos, dando enfoque para os cálculos.

\section{Analisando novas fontes do acervo da professora Myriam}

Nos arquivos do acervo da professora Myriam, além dos que foram analisados por Mendonça (2016), encontram-se os livros: Enciclopédia Ilustrada do Ensino Primário (EIEP) e Matemática Moderna - $3^{o}$ grau ( $M M-3^{\circ}$ grau). Também se faz presente o Plano Experimental da Delegacia Regional de Ensino de Juiz de Fora (PEDRE-JF). Buscando complementar o estudo já realizado, afere-se um olhar para esses documentos.

O livro EIEP possui capa dura na cor verde com as letras escritas em amarelo. É composto por 214 páginas, sendo 20 dessas dedicadas ao ensino de Geometria. São usadas ilustrações coloridas em todo o seu conteúdo. Foi publicado no ano de 1971, sob coordenação geral da professora Cleide Martins e sob direção editorial de Ciro Ney. O ensino de Geometria inicia-se na página 188, apenas com imagens de pirâmides e o título em azul. Os conteúdos são 
divididos em tópicos: (i) noções de geometria; (ii) ângulos; (iii) polígonos; (iv) figuras planas; (v) sólidos geométricos e, por fim, (vi) esfera (que não constam no livro, as páginas foram retiradas).

No primeiro deles, a autora e seus colaboradores definem a geometria como "[...] a ciência que tem por objetivo a medida de extensão, considerada nos três aspectos: a linha, a superfície e o volume [...]" (MARTINS, 1971, p. 191). O exemplo dado para compreender o conceito é o de um lago: a superfície desse lago e a linha, que forma o seu contorno, são os conjuntos de pontos onde termina a água e começa a terra. Os autores defendem que, por uma série de abstrações sobre as formas dos objetos, pode-se considerar as figuras e as formas geométricas, pois, segundo eles, o estudo tem como ponto de partida um conjunto de noções primitivas os quais emergem através dos sentidos.

Ponto, reta, plano, linha, superfície, são considerados como entes geométricos, isto é, aqueles que devem ser definidos, mas dos quais se tem uma ideia formada, por intermédio da observação e da experiência. Não há definição para os elementos, mas são dados exemplos para serem percebidos: o ponto observando um grão de areia, uma ponta de agulha; a reta observando um fio esticado, um traço feito com o auxílio de uma régua; o plano observando o chão onde pisamos, uma folha de papel, a parede de uma sala; a linha observando uma estrada, um fio de seda, um risco deixado pelo lápis; a superfície observando as partes visíveis dos corpos e objetos. Além disso, o ponto, a reta e o plano são tidos como fundamentais.

Uma figura é definida como um conjunto de pontos e são classificadas em planas ou não planas. Quando os pontos das figuras não estão em um mesmo plano, os autores classificam-nas como sólido geométrico. Em sequência, são estudadas as figuras e os sólidos geométricos. Inicia-se pelo estudo das linhas, que, de acordo com os autores, pode ser considerada como o encontro de duas superfícies ou como a união de uma série de pontos. As linhas são classificadas em: pontuadas (formadas por pontos separados entre si); interrompidas (formadas por pequenos segmentos de linhas) e cheias (formadas por pontos bem unidos). Sobre as linhas retas são estudados os conceitos de: retas, semirretas e segmentos de reta. Outros tipos de linhas são mostrados na enciclopédia, tais como: linha curva (os pontos mudam constantemente de direção); linha mista (formada por retas e curvas); linha quebrada (formada por duas ou mais porções de retas, em sentidos diferentes); linha sinuosa (curvas desconcentradas). As linhas curvas, quebradas e mistas são classificadas, pelos autores, em abertas (quando seu início não coincide com o seu fim) e em fechadas (quando o seu início coincide com o seu fim). Além disso, os autores apresentam as ideias de linhas abertas e fechadas simples (não há cruzamentos em seu traçado) e não simples (há algum cruzamento em seu traçado. A Figura 5 ilustra as linhas trabalhadas na enciclopédia. Nas Figuras 7, 8, 10 e 11 podem ser observados alguns exemplos da vida prática. 
Figura 6: exemplos de linhas curva, mista, quebrada, sinuosa, abertas e fechadas

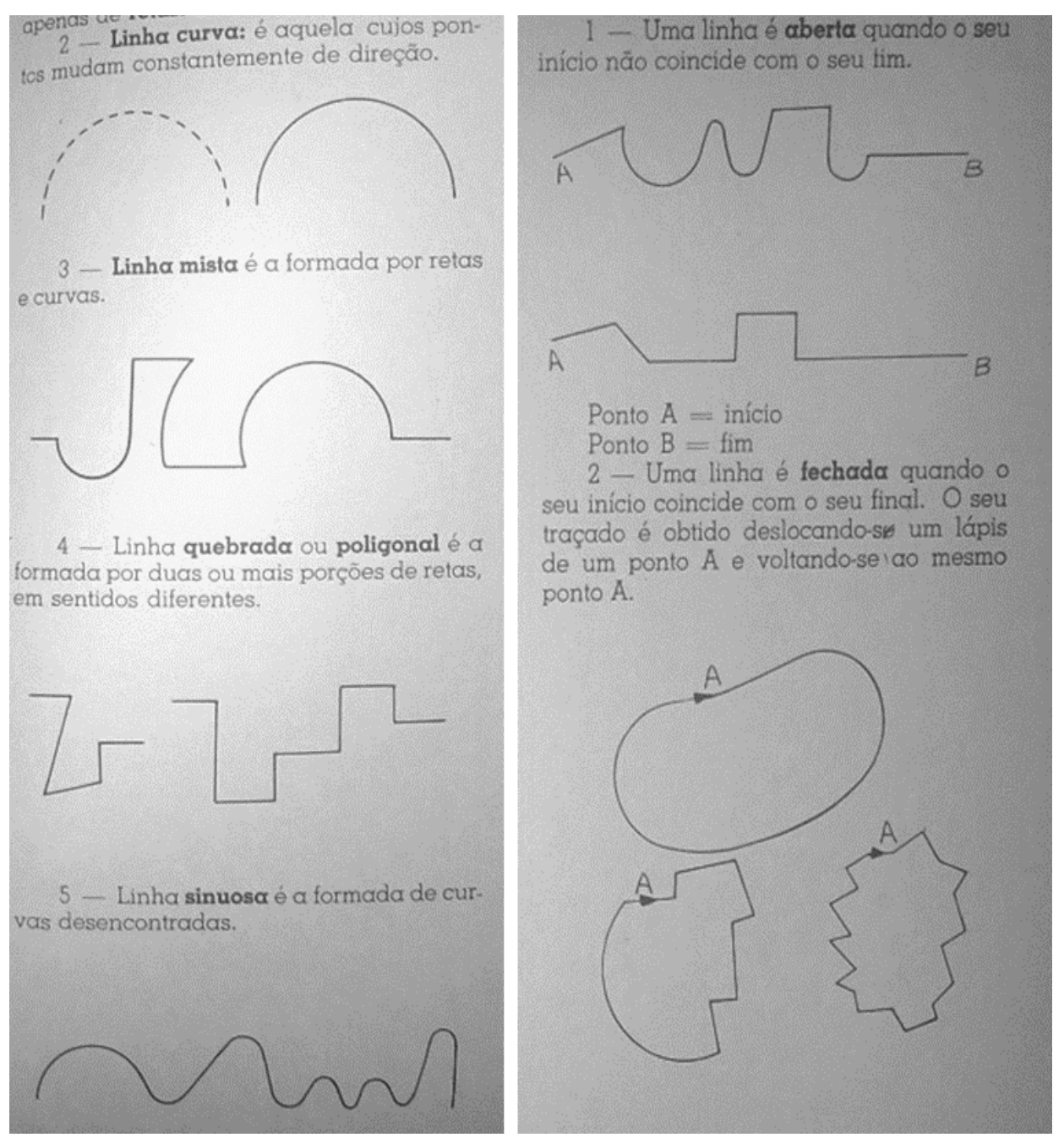

Fonte: recorte da EIEP

Figura 7: exemplo de linha aberta simples

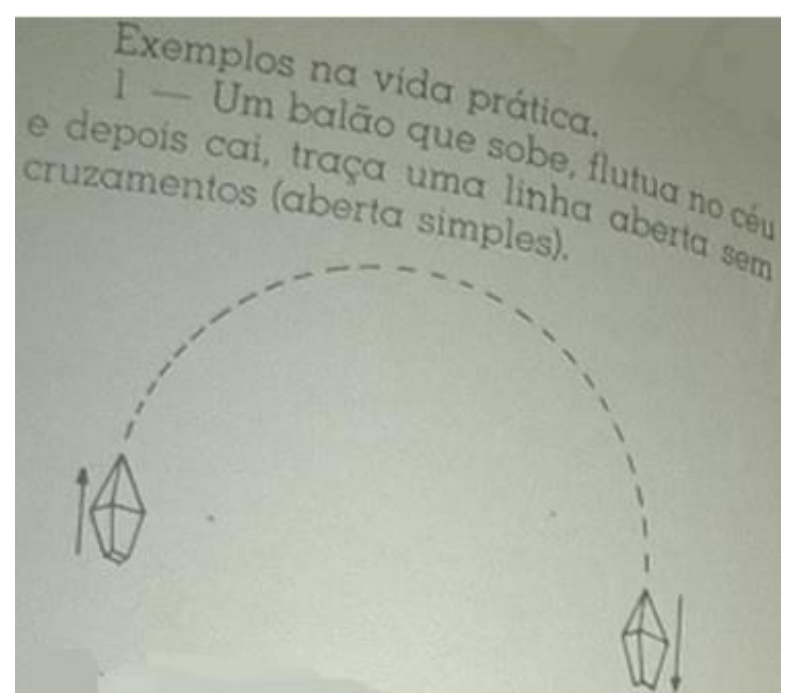

Fonte: recorte da EIEP

ISSN 2526-2882 
Transcrição: 1 - Um balão que sobe, flutua no céu, e depois cai, traça uma linha aberta sem cruzamentos (aberta simples).

Figura 8: exemplo de linha fechada simples

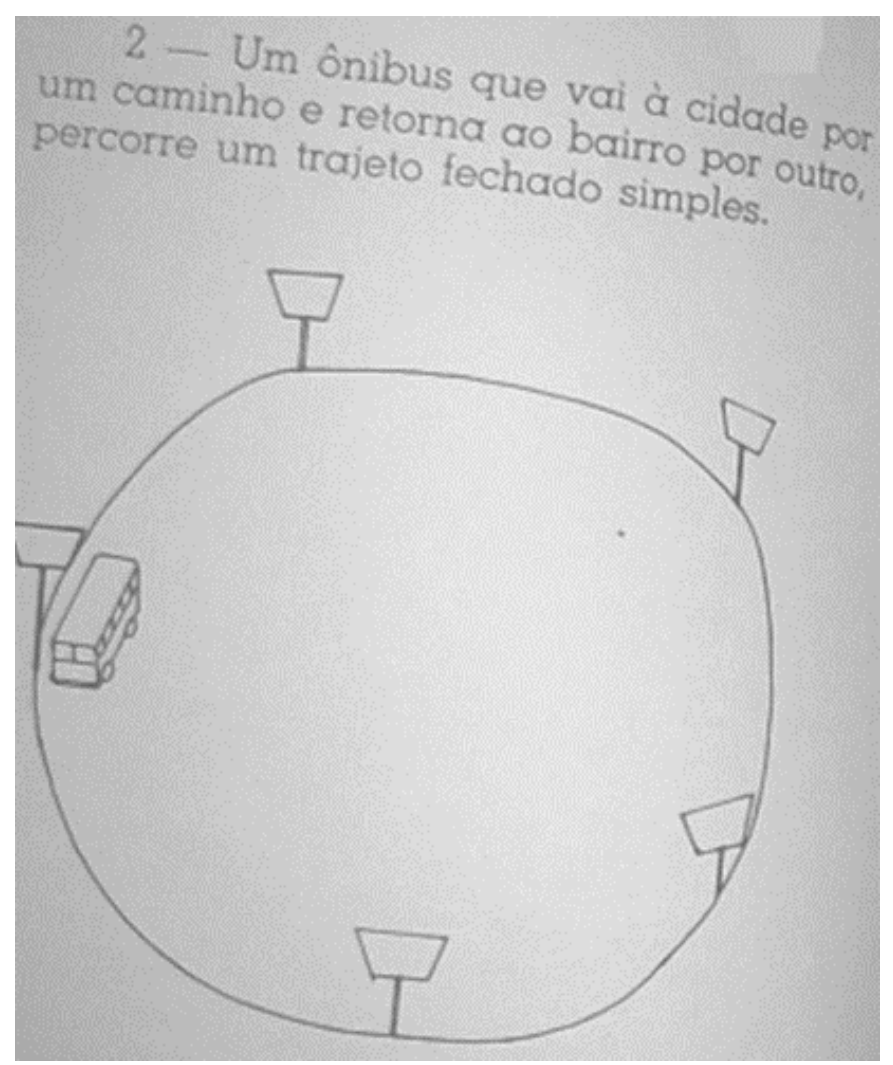

Fonte: recorte da EIEP

Transcrição: 2 - Um ônibus que vai à cidade por um caminho e retorna ao bairro por outro, percorre um trajeto fechado simples.

Figura 9: linha aberta não simples

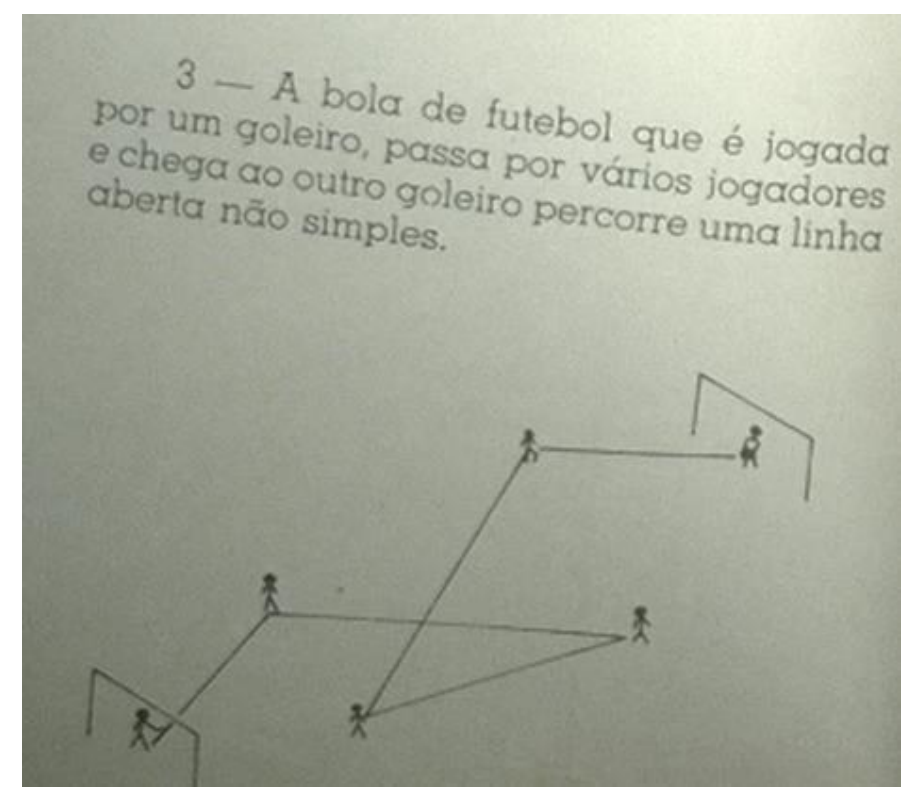

Fonte: recorte da EIEP

ISSN 2526-2882

*37* 
Transcrição: 3 - A bola de futebol que é jogada por um goleiro, passa por vários jogadores e chega ao outro goleiro percorre uma linha aberta não simples.

Figura 10: linha fechada não simples

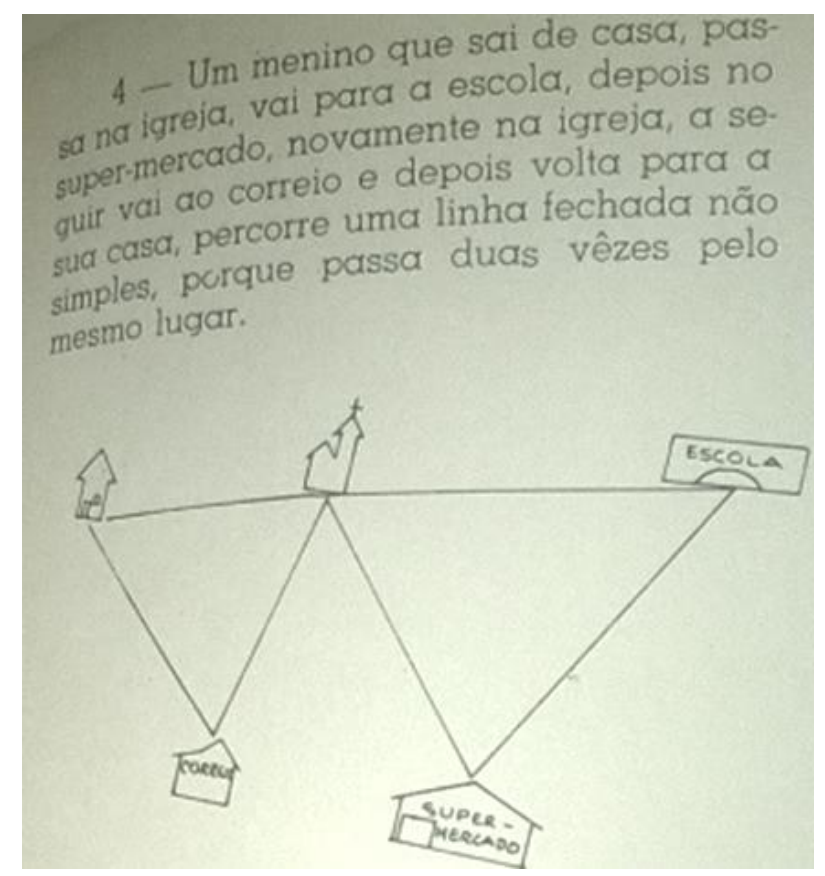

Fonte: recorte da EIEP

Transcrição: 4 - Um menino que sai de casa, passa na igreja, vai para a escola, depois no supermercado, novamente na igreja, a seguir vai ao correio e depois volta para a sua casa, percorre uma linha fechada não simples, porque passa duas vezes pelo menos lugar.

Figura 11: linha curva fechada

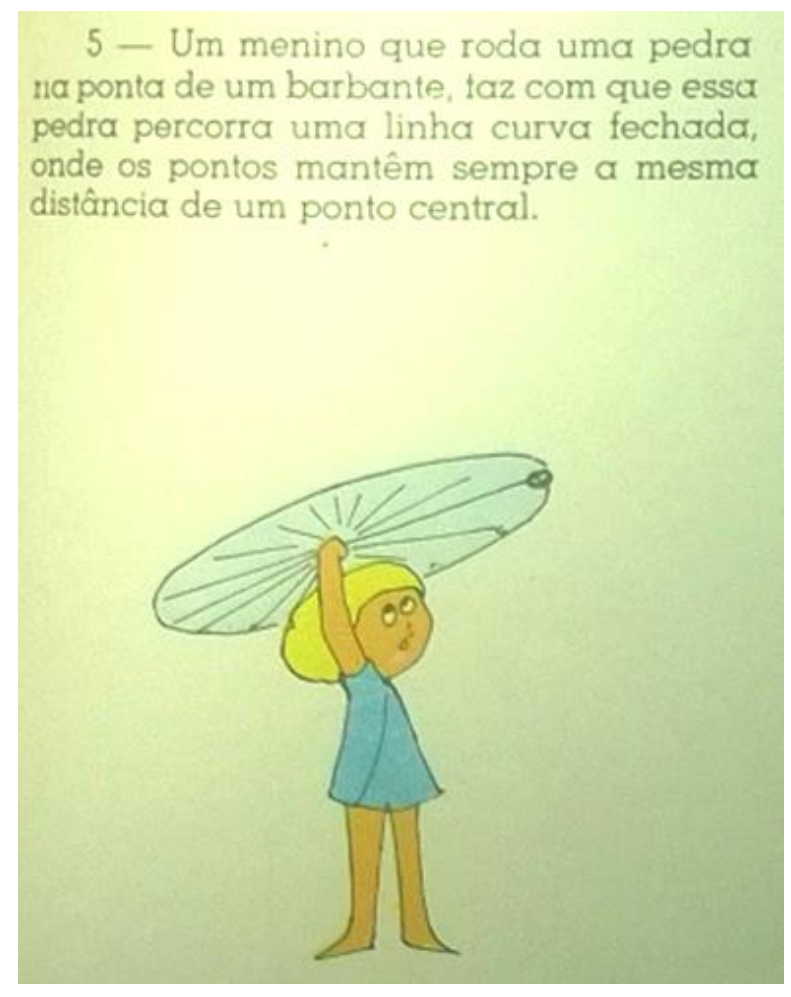

Fonte: recorte da EIEP

ISSN 2526-2882 
Transcrição: 5 - Um menino que roda uma pedra na ponta de um barbante, faz com que essa pedra percorra uma linha curva fechada, onde os pontos mantêm sempre a mesma distância de um ponto central.

A esse último exemplo, os autores relacionam o conceito de circunferência, como sendo uma "[...] curva fechada simples formada por pontos que conservam a mesma distância do centro [...]" (MARTINS, 1971, p. 195).

Dando sequência ao conteúdo, são apresentadas as retas e suas diferentes posições (isoladas ou relacionadas com outras retas). As posições absolutas das retas são denominadas de horizontal, de vertical e de inclinada. Por sua vez, as posições relativas, de paralelas, de convergentes, de perpendiculares e de divergentes. Seguem-se alguns exemplos: uma maçã caindo de uma árvore representa uma linha vertical; observando o bonde parado sobre os trilhos se observam várias posições da reta; as cordas do violão; a Torre de Pisa. O conteúdo abordado a seguir refere-se a medidas de ângulos. Observa-se, nele, a menção ao transferidor, definido como "[...] um semicírculo dividido em 180 partes iguais chamadas graus [...]" (MARTINS, 1971, p. 200).

Para se referir aos polígonos, a autora utiliza conceitos de linhas fechadas simples. Ela classifica os polígonos quanto a seus lados e apresenta a nomenclatura de alguns polígonos especiais. No livro, o primeiro polígono a ser trabalhado é o triângulo, apresentando-se sua definição, seus elementos, suas classificações quanto aos lados (equilátero, isósceles e escalenos) e quanto aos seus ângulos (acutângulo, retângulo e obtusângulo). Em sequência, são observados os quadriláteros (paralelogramo, retângulo, quadrado, losango, trapézio), trazendo suas definições, seus elementos e suas classificações, sem conceituar áreas ou perímetros. O conteúdo do livro é finalizado com o estudo da circunferência, o qual a autora define como uma linha curva fechada com todos os pontos a uma mesma distância de um ponto central interior, definindo assim o centro, o raio, o diâmetro, a diferença entre círculo e circunferência, os arcos e as cordas. A parte destinada aos sólidos geométricos, que constam no índice do livro, foi retirada (páginas não constam no livro analisado).

O livro $\mathrm{MM}-3^{\mathrm{O}}$ grau possui capa colorida e foi escrito pela professora Carolina Rennó Ribeiro de Oliveira. Já na capa consta que a professora foi diretora do curso rápido 9 de Julho. Especificamente, o ensino de Geometria é tratado somente no capítulo VIII, embora em capítulos anteriores a autora já apresente as ideias de medidas de capacidade e de massa. A primeira frase do capítulo refere-se à presença da Geometria em nossa vida diária, para, em seguida, apresentar os sólidos geométricos: prisma, pirâmide, cubo, paralelepípedo, cilindro, cone e esfera. Há, na sequência, um exercício para completar com o nome do sólido geométrico que o objeto lembra: por exemplo, o copinho de sorvete que tem a forma de um cone, entre outros. 
As ideias de linhas também estão presentes, bem como suas classificações: reta, curva, quebrada, mista, horizontal, vertical e inclinada. Além disso, também são definidas as posições relativas entre duas retas, tais como: perpendiculares, oblíquas, paralelas, convergentes e divergentes. Nas imagens, as ideias de linhas convergentes e divergentes não são muito explicativas, como se pode observar na Figura 12 a seguir.

Figura 12: ilustração das posições relativas entre retas

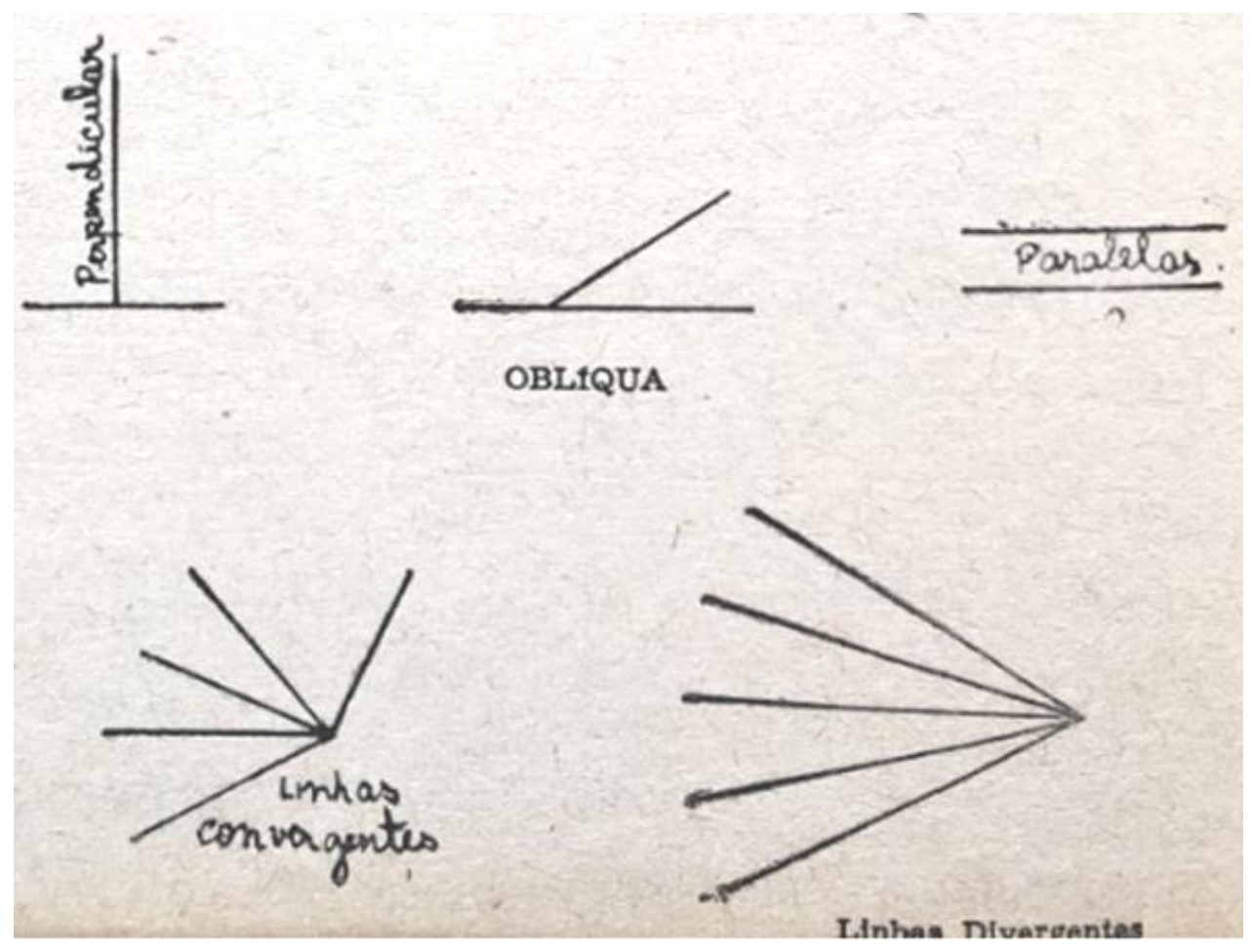

Fonte: $\mathrm{MM}-3^{\mathrm{o}}$ grau

Por meio da observação das faces de um cubo, apresenta-se o quadrado. O losango é considerado como fruto de uma deformação na superfície de um quadrado: os vértices opostos são esticados como se fossem feitos de borracha. O retângulo é encontrado nas faces dos paralelepípedos e o mesmo processo feito para os losangos é utilizado para os paralelogramos, esticando-se dois vértices opostos do retângulo. O triângulo nas faces da pirâmide, e são classificados em equiláteros, isósceles e escalenos. A autora define os quadriláteros e os triláteros (três lados). O círculo é encontrado nas bases do cilindro e do cone. A autora explica como obter um círculo com 1 folha de papel, seguindo os passos: dobrar uma folha em 4 , depois em 8, depois em 16 e cortar arredondando obtendo-se assim um círculo, conforme a Figura 13). 
Figura 13: como obter um círculo com uma folha

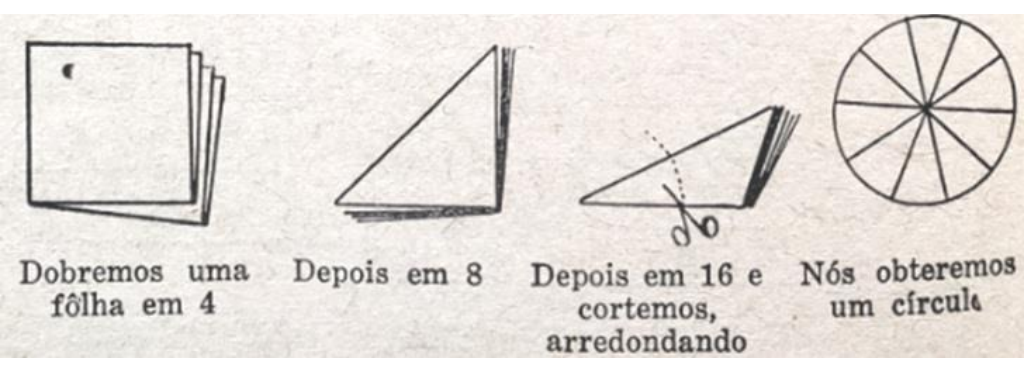

Fonte: $\mathrm{MM}-3^{\mathrm{o}}$ grau

Dando sequência, a autora define circunferência como uma linha curva fechada com todos os pontos à mesma distância de um ponto no interior, chamado centro; além de mostrar como traçar utilizando um compasso. Dessa forma, ela define o raio. Em seguida, são trabalhadas as ideias de ângulo, suas classificações (retos, agudos e obtusos), com dobraduras de folhas retangulares. Para tanto, a autora utiliza uma circunferência, dividindo-a em 360 partes, concluindo que uma circunferência mede $360^{\circ}$, que um quarto dela mede $90^{\circ}$ por ter retas perpendiculares. Novamente aparece o transferidor, com imagens mostrando como usálo para medir os ângulos. Os exercícios são de completar com números correspondentes, ou com verdadeiro (v) ou falso (f).

São trabalhadas, a seguir, a ideia de perímetro do quadrado, utilizando um exemplo de colocar renda em volta de uma toalha no formato de quadrado e questionando quantos metros de renda serão necessários para fazer esse processo. Na sequência, há uma gama de exercícios que utilizam a aritmética para calcular o perímetro, os lados, os gastos necessários, entre outros, que envolvem a ideia de perímetro. Também são abordadas as ideias de perímetro de retângulos e de triângulos, com exemplos e exercícios.

No material da professora Myriam encontra-se a $3^{\mathrm{a}}$ parte do PEDRE-JF, publicado em 1972. Fazem parte da equipe organizadora do plano: Gilda Pazzini Lodi; Maria Célia Bueno; Maria Helena Andrade; Maria Helena Teixeira Neves; Rosa Emília de Araújo Mendes; Sônia Fiuza da Rocha Castilho e Yara Terezinha de Moura Cotta. Na parte destinada ao ensino de Geometria, encontram-se, na primeira página, os objetivos, divididos em conhecimentos e em habilidades de: aqueles apresentam os tópicos a serem abordados, a saber, “[...] conceito de ponto, espaço, reta, semi-reta, segmento de reta; noção de paralelas e concorrentes; conceito de ângulos de diversos tipos; compasso e transferidor para ângulos; régua para linhas retas [...]" (LODI; et al, p. 146); esse se refere a “[..] traçar uma reta, semi-reta, segmento de reta; traçar paralelas e concorrentes; traçar ângulos; usar adequadamente instrumentos, no traçado de linhas e ângulos; usar corretamente o vocabulário específico; aplicar os conhecimentos adquiridos em situações práticas da vida [...]” (p. 146).

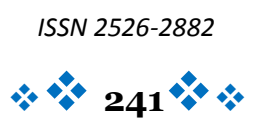


O PEDRE-JF está organizado em 4 colunas, sendo a primeira destinada ao conteúdo, a segunda para as atividades, a terceira para o material e a última para avaliação. Inicia-se com uma revisão de curvas abertas e fechadas e de figuras (círculo, quadrado, triângulo, retângulo e losango). Em seguida, formaliza-se conceitos de espaço e de ponto, tais como: “[...] espaço é o conjunto de todos os pontos [...]" e "[...] ponto é o primeiro sinal que fere o espaço [...]" (LODI; et al, p. 147). Como material sugerido, tem-se folhas mimeografadas e bolas, caixas, dados, figuras recortadas em cartolinas, alfinetes, giz, desenhos feitos pelo professor, e as atividades envolvem esse material. Dentre as atividades, há uma que sugere que sejam feitos desenhos de vários pontos de tamanhos diferenciados para que os alunos possam reconhecer aquele que melhor representa um ponto. Segue, então, que “[...] o ponto é a mais simples das figuras geométricas. O ponto não possui nenhuma dimensão. Podemos localizar a posição de um ponto. Um ponto é sempre nomeado por uma letra maiúscula [...]” (p. 148).

Na sequência, o conceito de retas é inserido, indicando para que seja apresentada para a classe uma paisagem previamente desenhada pelo professor para que as crianças identifiquem as linhas curvas e retas. Com barbante, os autores pedem para que os professores convidem os alunos a desenharem dois pontos distintos e nomearem esses pontos, traçando linhas que os unam, tendo linhas curvas e retas. Dessa forma, os alunos perceberão que "[...] a reta é a mais simples das curvas; como toda linha, possui uma única dimensão, o comprimento [...]" (p. 150).

Dando sequência aos conteúdos trabalhados, apresentam-se as posições da reta: vertical, horizontal e inclinada. Para representá-las, a sugestão é de que o professor desenhe um ponto de origem para as retas e construa-as conforme sua classificação, mostrando, visualmente, às crianças. Além disso, há também retas perpendiculares e oblíquas. O material indicado para ser utilizado vai de garrafa à palitos de fósforos. Com as retas obliquas, a sugestão é de trabalhar os ângulos retos, agudos e obtusos. Dando sequência, estão presentes as retas paralelas e concorrentes, com sugestão de trabalharem com os palitos de fósforo para visualizarem as posições. As semirretas são trabalhadas com um desenho de segmento de reta $\mathrm{AB}$ e um ponto $\mathrm{X}$ marcado entre os extremos, para que as crianças percebam as semirretas ali presentes. Como material para essas atividades, sugere-se o caderno pautado e objetos da sala de aula. Os segmentos de reta são discutidos através desses dois pontos A e B no desenho anterior. Os materiais utilizados são régua, fita métrica.

Para o conteúdo referente aos ângulos, o material indicado, inicialmente, é o relógio de papelão, mostrando às crianças a região compreendida por um ângulo, que está entre dois ponteiros desse relógio. Formalizando o conceito de ângulos, os autores afirmam que o "[...] ângulo é a figura formada por 2 semi-retas que têm a mesma origem [...]” (p. 154). Com palitos de fósforos, a ideia é que o professor mostre aos alunos o que é um ângulo reto, agudo, obtuso 
e raso. O conceito de bissetriz de um ângulo é apresentado como "[...] a semi-reta que, tendo por origem o vértice do ângulo o divide ao meio [...]” (p. 156). Como material são indicados o transferidor, o compasso, folhas mimeografadas e de papel. A sugestão é de que o professor leve os alunos a usar os instrumentos para medir os ângulos.

Na bibliografia para o professor, encontram-se dois livros de Dienes, quais sejam: Lógica e jogos lógicos - Conjuntos, Números e potências e A Matemática moderna no ensino primário. Encontra-se, também, o Curso moderno de Matemática para Escola Elementar, de Manhúcia Perelberg Liberman e seus colaboradores e dois livros da Rizza de Araújo Porto (Ver, sentir, Descobrir Aritmética e Frações na Escola Elementar). Há uma bibliografia para o aluno, na qual pode ser encontrado um livro da Henriqueta de Carvalho, Matemática Moderna $-2^{o}$ grau, além do livro anteriormente citado da Manhúcia.

\section{Considerações finais}

Buscando por novas fontes no acervo da professora Myriam, para complementar estudos já realizados sobre o ensino de Geometria para as crianças em tempos de matemática moderna no estado de Minas Gerais, tendo como referência práticas da professora sob o significado de apropriação defendida por Chartier (1990), encontramos três novas fontes para análise, quais sejam: os livros Enciclopédia Ilustrada do Ensino Primário (EIEP) e Matemática Moderna - $3^{o}$ grau (MM - $3^{o}$ grau) e o Plano Experimental da Delegacia Regional de Ensino de Juiz de Fora (PEDRE-JF). Seguindo os caminhos traçados até então, optamos por manter as categorias de análise já elencadas em pesquisas anteriores, a saber: (i) presença da topologia; (ii) construções geométricas; (iii) linguagem de conjuntos; (iv) referência a Dienes e a Piaget; (v) uso de imagens e diagramas; (vi) uso de materiais didáticos; e, por fim (vii) justificativa de propriedades.

A EIEP possui ilustrações coloridas, publicada em 1971. Nela, observamos a presença da geometria plana, pois a parte destinada à geometria espacial foi retirada do livro analisado (constata-se esse fato por esses tópicos estarem presentes no índice do livro). Desde o estudo das linhas (curva, mista, quebrada, sinuosa, abertas, fechadas, simples e não simples). Parecenos apresentar com esses conceitos certas ideias iniciais de topologia, o que era defendido pelo ideário do MMM para o ensino de geometria. Não s]ao observadas referências às teorias de Piaget e Dienes. Das categorias elencadas, temos a (i) e a (iii).

No livro $\mathrm{MM}-3^{\mathrm{o}}$ grau, há a presença da geometria plana e espacial. Também são encontradas as ideias de linhas abertas e fechadas, o que pode ser relacionado com as ideias de topologia. Alguns conceitos são trabalhados utilizando a teoria de conjuntos. Há indicações de construções geométricas, utilizando barbantes, fazendo recortes, compassos e transferidores. Não há referências à Piaget e Dienes. Observamos as categorias (i), (ii) e (vi). 
No PEDRE-JF também são observadas as ideias de curvas abertas e fechadas. Nele podemos notar a utilização da teoria de conjuntos ao se definir alguns conceitos geométricos, como por exemplo quando se fala de espaço como conjunto de todos os pontos. Há indicação de materiais, tais como barbante, relógio de papelão, garrafas, palitos de fósforo. Nele, encontram-se algumas obras de Piaget na bibliografia. Há uma bibliografia destinada aos alunos, e, nela, encontramos um livro da Henriqueta de Carvalho (uma das autoras da CCMMEP, analisada em pesquisas anteriores). Das categorias, identificamos (i), (iii), (iv) e (vi).

Com a atual análise, envolvendo novas fontes que pertenciam à professora Myriam, a professora dispunha de materiais que, cada um a sua medida, carregava traços do MMM. Nos materiais analisados anteriormente, a CCMMEP estava mais alinhada ao ideário do MMM. Desses novos materiais, o PEDRE-JF é o que mais contém marcas do movimento. De certa forma, a professora estava, ao menos, conhecendo algumas das ideias inovadoras do movimento de modernização do ensino de Matemática. Contudo, em seus cadernos, mesmo feitos em épocas distintas, não apresentam traços relacionados ao movimento. Mendonça e Oliveira (2016) apontam que a cultura escolar é afeita às permanências. As propostas inovadoras são divulgadas, porém nem sempre são incorporadas na prática. Para o ensino de geometria percebe-se que a essência na exploração das características e propriedades das figuras geométricas permanece, enquanto outros elementos do ideário moderno se encontram justapostos numa tentativa de considerá-los sem que de fato estejam articulados ou até mesmo substituindo a geometria euclidiana.

\section{Referências}

ARRUDA, J. P. Histórias e práticas de um ensino na escola primária: Marcas e Movimentos da Matemática Moderna. Tese de Doutorado (Doutorado em Educação). Programa de Pós-Graduação em Educação Científica e Tecnológica, Universidade Federal de Santa Catarina, Florianópolis, 2011.

BLOCH, M. Apologia da História ou Ofício do Historiador. Rio de Janeiro: Jorge Zahar Editor Ltda, 2002.

CARVAlHO, H.; FERREIRA, T. Curso completo de Matemática Moderna para o Ensino Primário. V. 1-5. s.l: Editora Renovação, s.d. Disponível em https://repositorio.ufsc.br/handle/123456789/158566. Acesso em 29 de agosto de 2018, às 14 ho5.

CHARTIER, R. A história cultural - entre práticas e representações. Rio de Janeiro: Bertrand Brasil, 1991. 
CHERVEL, A. História das disciplinas escolares: Reflexões sobre um campo de pesquisa. Teoria \& Educação. Porto Alegre, n. 2, p. 177-229, 1990.

CHOPPIN, A. O historiador e o livro escolar. História da Educação. Pelotas, v. 11, p. 5-24, p. 5-24, 2002.

JULIA, D.; SOUZA, G (trad.) A Cultura Escolar como Objeto Histórico. Revista Brasileira de História da Educação. Maringá, n. 1, p. 9-43, 2001.

LEME DA SILVA, M. C.; VALENTE, W. R. (org.) A Geometria nos primeiros anos escolares: história e perspectivas atuais. Campinas: Papirus Editora, 2014.

LODI, G. P. et al. Plano Experimental da Delegacia Regional de Ensino de Juiz de Fora. $3^{\text {a }}$ parte do programa. Juiz de Fora: Secretaria de Estado da Educação ETRA, 1972.

MARTINS, C., Enciclopédia Ilustrada do Ensino Primário (pedagógica). V II. Serra: Editora Formar, 1971.

MEDINA, D. de A. F. A Produção oficial do Movimento da Matemática Moderna para o ensino primário no Estado de São Paulo (1960 - 1980). Dissertação de Mestrado (Mestrado em Educação Matemática), Programa de Pós-Graduação em Educação Matemática, Pontifícia Universidade Católica de São Paulo, São Paulo, 2007.

MENDONÇA, T. N. Que Geometria ensinar às crianças em tempos de Matemática Moderna? Referências e práticas de uma professora da cidade de Juiz de Fora. Dissertação de Mestrado (Mestrado em Educação Matemática), Programa de PósGraduação em Educação Matemática, Universidade Federal de Juiz de Fora, Juiz de Fora, 2016.

MINAS Gerais, Programa do Ensino Primário de Minas Gerais. V. 1-4. Belo Horizonte: Imprensa Oficial, 1965. Disponível em https://repositorio.ufsc.br/handle/123456789/104802. Acesso em 29 de agosto de 2018, às 14 ho5.

OLIVEIRA, M. C. A. et al. O movimento da Matemática Moderna: história de uma revolução curricular. Juiz de Fora: Editora da UFJF, 2011.

OLIVEIRA, M. C. A. Profissionalidade para o ensino de geometria: um estudo a partir da legislação. Revista de História da Educação Matemática - HISTEMAT. Ano 1, n. 1, 2015, p. 189-2002, 2015.

OLIVEIRA, M. C. A. Profissionalidade para o ensino de geometria: um estudo a partir da legislação. Revista de História da Educação Matemática - HISTEMAT. Ano 1, n. 1, p. 189-202, 2015. 
OLIVEIRA, M. C. A., MENDONÇA, T. N. Saberes para uma geometria moderna no ensino primário - MG (1960-1970). REMATEC. Rio Grande do Norte, ano 11, n. 23, 2016, p. 86, 2016.

PIAGET, J. e INHELDER, B. A representação do espaço na criança. Porto Alegre: Artes Médicas, 1993.

PROST, A. Douze leçons sur l'histoire. Paris: Éditions du Seuil, 1996.

PROST, A. Doze lições sobre a história. Belo Horizonte: Autêntica Editora, 2008.

VALENTE, W. R., História da Educação Matemática: interrogações metodológicas, REVEMAT - Revista Eletrônica de Educação Matemática, v. 22, p. 28-29, 2007.

VALENTE, W. R., Que geometria ensinar? Uma breve história da redefinição do conhecimento elementar matemático para crianças. Pró-Posições (UNICAMP. Impresso). Campinas, v. 24, p. 159-178, 2013.

\section{Biografia Resumida}

Thiago Neves Mendonça: Licenciado em Matemática pela Universidade Federal de Viçosa (UFV). Mestre em Educação Matemática pela Universidade Federal de Juiz de Fora (UFJF). Professor do Instituto Federal de Minas Gerais (IFMG) - campus Ouro Preto.

Link Lattes: http://Link Lattes.cnpq.br/5457032233864004

e-mail: thiago.neves@ifmg.edu.br 